Tropical Journal of Pharmaceutical Research March 2020; 19 (3): 651-659

ISSN: $1596-5996$ (print); 1596-9827 (electronic)

(C) Pharmacotherapy Group, Faculty of Pharmacy, University of Benin, Benin City, 300001 Nigeria.

Original Research Article

http://dx.doi.org/10.4314/tjpr.v19i3.28

\title{
Comparative pharmacokinetic study of five flavonoids in normal rats and rats with gastric ulcer following oral administration of Mongolian medicine, Shudage - 4 by UPLC - ESI - MS/MS
}

\author{
Xin Jia ${ }^{1,2,3}$, Yinfei $\mathrm{Du}^{3}$, Jia $\mathrm{Xu}^{4}$, Yu Dong ${ }^{1,2,5 *}$ \\ ${ }^{1}$ School of Chinese Materia Media, Tianjin University of Traditional Chinese Medicine, Tianjin 300193, ${ }^{2}$ Engineering Technology \\ Research Center of Pharmacodynamic Substance and Quality Control of Mongolian Medicine in Inner Mongolia, Inner \\ Mongolia Medical University, Hohhot 010110, ${ }^{3}$ Department of Pharmacy, The Affiliated Hospital of Inner Mongolia Medical \\ University, Hohhot 010059, ${ }^{4}$ School of Foreign Language, Inner Mongolia Medical University, Hohhot 010110, ${ }^{5}$ College of \\ Pharmacy, Inner Mongolia Medical University, Hohhot 010110, China
}

*For correspondence: Email: dongyu010@163.com; Tel: +86-04716653084

Sent for review: 29 September 2019

Revised accepted: 23 February 2020

\begin{abstract}
Purpose: To develop a simple, rapid and sensitive ultra-performance liquid chromatography electrospray ionization-mass spectrometry (UPLC-ESI-MS/MS) method was developed and fully validated for the simultaneous determination of galangin, kaempferide, galangin-3-methylether kaempferol and quercetin in rat plasma after oral administration of Mongolian Medicine, Shudage-4 extracts.

Methods: The galangin, kaempferide, galangin-3-methylether, kaempferol and quercetin were separated on a $C_{18}$ column using $0.1 \%$ formic acid at a flow rate of $0.4 \mathrm{~mL} / \mathrm{min}$ and detected by a mass spectrometer in negative-ion mode with selected reaction monitoring (SRM) mode. Plasma samples were processed with a simple deproteinization technique using ethyl acetate and acetonitrile. Following the protein precipitation, the plasma samples were evaporated under gentle stream of nitrogen and analyzed by above method. Naringin was used as an internal standard (IS). Method validation was performed according to the Chinese Food and Drug Administration guidelines.

Results: A good linearity $\left(r^{2} \geq 0.9990\right)$ was showed by the UPLC - ESI - MS / MS method, the low limits of quantification for galangin, kaempferide, galangin-3-methylether, kaempferol and quercetin were 229.8, 78.8, 32.0, 123.7 and $137.8 \mathrm{ng} / \mathrm{mL}$, respectively. The results of inter-day and intra-day precisions met the experimental requirement $(<7.8 \%)$. The matrix effect and recovery efficiency of the five analytes were more than 72.9 and $88.7 \%$ respectively. The stability of the analytes were satisfactory. The UPLC - ESI - MS / MS method has been used for the five analytes' pharmacokinetics study successfully after gastrointestinal route of the Mongolian Medicine Shudage-4. The pharmacokinetic parameters showed significant differences $(P<0.05)$ between the normal and gastric ulcer groups. The metabolism and transport of the five analytes in gastric ulcer rates were faster than in normal rats after administration of Shudage - 4 extract. Double-peak phenomenon appeared in galangin, galangin - 3 - methylether and quercetin.

Conclusion: The results suggest that the metabolism and transport of Mongolian Medicine Shudage-4 in gastric ulcer rats is faster than in normal rats and may be enriched and acted on at the lesion site.

Keywords: UPLC - ESI - MS / MS; Mongolian medicine; Shudage - 4; pharmacokinetics; gastric ulcer

This is an Open Access article that uses a fund-ing model which does not charge readers or their institutions for access and distributed under the terms of the Creative Commons Attribution License (http://creativecommons.org/licenses/by/4.0) and the Budapest Open Access Initiative (http://www.budapestopenaccessinitiative.org/read), which permit unrestricted use, distribution, and reproduction in any medium, provided the original work is properly credited.

Tropical Journal of Pharmaceutical Research is indexed by Science Citation Index (SciSearch), Scopus, International Pharmaceutical Abstract, Chemical Abstracts, Embase, Index Copernicus, EBSCO, African Index Medicus, JournalSeek, Journal Citation Reports/Science Edition, Directory of Open Access Journals (DOAJ), African Journal Online, Bioline International, Open-J-Gate and Pharmacy Abstracts
\end{abstract}




\section{INTRODUCTION}

On account of the cold climate, meal-rich and wine-rich diet in Mongolia area, stomach diseases occur frequently. Over the years, the Mongolian people have accumulated rich experience in treatment of stomach diseases, and some unique Mongolian medicines have shown good curative effects in the treatment of stomach diseases.

Shudage - 4, which consists of galangal, purpurea halitium, costustoot and acorus gramineus soland, is a common prescription for stomach disorder. It has been widely used in clinical settings for treating stomach illness for hundreds of years in Mongolia [1]. Phytochemical studies have revealed that flavonoids, including galangin, kaempferide, galangin-3-methylether, kaempferol and quercetin, are major ingredients in Shudage-4 [2,3-5]. Their quality control and pharmacological efficacy have been reported [68]. The pharmacological activity of flavonoids has strong antioxidative action, free radical scavenging capacity, hepatoprotective effect, antibacterial action, anti-inflammatory, and anticancer activity [9]. In addition, antiviral activity has also been recognized since the 1940s, such as anti - human immunodeficiency virus (antiHIV), anti - herpes simplex virus (anti - HSV), and anti - dengue virus [10].

Several analytical methods based on high performance liquid chromatography (HPLC), ultraviolet spectrophotometry (UV), liquid chromatograph-mass spectrometer (LC-MS) have been reportedly used to evaluate the main flavonoids in rat plasma. In order to better separation in plasma samples, HPLC and UV methods not only required a long chromatographic process to avoid the interference, but also the unsatisfactory sensitivity for determinations was the most important problem. Furthermore, not all flavonoids have active chromophores at appropriate wavelengths or fluorescent agents [11]. Ultra-performance liquid chromatographyelectrospray ionization-mass spectrometry (UPLC-ESI-MS/MS) method is currently attracting considerable interest as a simple and sensitive method in qualitative and quantitative analysis, which can overcome most of the abovementioned limitations [12].

Pharmacokinetic studies of Mongolian medicines play an important part in evaluating clinical efficacy and guiding rational drug usage. Pharmacokinetic studies play an important role in evaluating the rationally of Mongolian medicine prescriptions. No reported on the pharmacokinetic of Shudage - 4 extract and no simultaneous determination of galangin, kaempferide, galangin-3-methylether, kaempferol and quercetin by the UPLC - ESI - MS/MS method. In consequence, the pharmacokinetics of the above analytes in gastric ulcer model and normal rat plasma were compared.

To exert a biological effect, the herbs of prescriptions must act on the target tissues after oral administration. The pharmacokinetic studies are responsible for determine concentration of the main bioactive contents in vivo, elucidate efficacy, explain drug action, and optimize dosage.

Therefore, to further investigate the pharmacokinetics and interaction, a rapid, accurate and sensitive UPLC-ESI-MS/MS method was developed for the simultaneous determination of galangin, kaempferide, galangin-3-methylether, kaempferol and quercetin in rat plasma after oral administration of Shudage - 4 extracts using naringin as internal standards.

\section{EXPERIMENTAL}

\section{Chemicals and reagents}

Galangin-3-methylether (NO.20170919001), kaempferide (NO.20160328), kaempferol (NO. MUST - 17040502) and quercetin (NO.100081200406) and internal standard (IS) Naringin (NO.110722 - 201714) were obtained from the National Institute for the Control of Pharmaceutical and Biological Products (Beijing, China). Galangin was previously isolated and identified by MS and NMR spectra. Their purity was all above $98 \%$ analyzed by HPLC. HPLCgrade methanol and formic acid were purchased from Thermo Fisher Scientific (CN, USA).

\section{Instrumentation and chromatographic conditions}

Samples were analyzed by a TSQ quantum ultramass spectrometric detector with electrospray ionization source (ESI) (Termo Scientific, USA) coupled with a Dionex Ultimate 3000 ultra performance liquid chromatography system. The operating conditions for mass were as follows: $3000 \mathrm{~V}$ for spray voltage, $300{ }^{\circ} \mathrm{C}$ for vaporizer temperature, $35 \mathrm{AU}$ for sheath gas (Arb) pressure; $10 \mathrm{AU}$ for auxiliary gas (Arb) pressure; $5 \mathrm{AU}$ for ion sweep gas (Arb) pressure, and 300 ${ }^{\circ} \mathrm{C}$ for capillary temperature. All the operations were under the condition of Xcalibur software (Thermo Scientific, USA). 
Preparation of total flavonoids of Shudage -4

The Shudage - 4 composed of the dry root of Alpinia officinarum Hance (400 g), Aucklandia lappa Decne (100 g), Acorus tatarinowii Schott $(100 \mathrm{~g})$ and Halite Violaceous (200 g) were extracted and refluxed for 2 hours with $70 \%$ ethanol $(1: 10, w / v)$. The extracting solution was combined, and concentrated by reduced the pressure. The concentrated eluent was loaded on macroporous resin column (D101 type), and elution with $\mathrm{H}_{2} \mathrm{O}$ and $50 \%$ aqueous ethanol in turn. Collecting the $50 \%$ aqueous ethanol elution and obtaining the flavonoid fraction of Shudage $4[8,13]$.

\section{Standards' and quality control samples' preparation}

The standard stock solution of the five analytes were prepared with the final concentration of $229.8 \mu \mathrm{g} / \mathrm{mL}$ for galangin, $3200.0 \mu \mathrm{g} / \mathrm{mL}$ for galangin-3-methylether, $788.0 \mu \mathrm{g} / \mathrm{mL}$ for kaempferide, $123.7 \mu \mathrm{g} / \mathrm{mL}$ for kaempferol, 137.8 $\mu \mathrm{g} / \mathrm{mL}$ for quercetin, respectively.

The stock solutions and spiking blank plasma were mixed to produce a series of working solutions, which were 229.8-22984.0 ng/mL for galangin; 32.0-3200.0 ng/mL for galangin - 3 methylether; $78.8-7880.0 \mathrm{ng} / \mathrm{mL}$ for kaempferide; 123.7-12366.0 ng/mL for kaempferol; 137.8$13780.0 \mathrm{ng} / \mathrm{mL}$ for quercetin. The quality control samples were produced at concentrations of $574.6,2298.4$, and $22984.0 \mathrm{ng} / \mathrm{mL}$ for galangin, $80.0,320.0$, and $3200.0 \mathrm{ng} / \mathrm{ml}$ for galangin-3methylether, $344.5,1378.0$, and $13780.0 \mathrm{ng} / \mathrm{mL}$ for kaempferide, 3019.5, 12366.0, and 123660.0 $\mathrm{ng} / \mathrm{mL}$ for kaempferol, and 344.5, 1378.0, and $13780.0 \mathrm{ng} / \mathrm{mL}$ for quercetin. The standard stock solutions and the working solutions were stored at $4{ }^{\circ} \mathrm{C}$, and the quality control samples were stored at $-20^{\circ} \mathrm{C}[14]$.

\section{Induction of model rats}

All animal protocols were approved by the Committee of Inner Mongolia medical university on Ethics of Animal Experiments (approval no. YKD20190331). Animals were treated in accordance with Guide for the Care and Use of Laboratory Animals (8th edition, National Academies Press). Wistar rats were housed in environmentally controlled quarters (about 23 $\left.25{ }^{\circ} \mathrm{C}\right)$ under a light-dark cycle $(12 \mathrm{~h}$ : $12 \mathrm{~h})$ for seven days before experiment. Twelve Wistar rats $(7 \sim 8$ weeks old, weighing $280 \sim 300 \mathrm{~g}$ ) were split into two, half the rats were put into model group, and another half in normal group. The model group rats were given a $56 \%$ Chinese spirits $3 \mathrm{ml} /$ day for three days by intragastric administration and the normal group rats were given physiological saline.

\section{Plasma sample preparation}

Frozen plasma was thawed at room temperature, and $400 \mu \mathrm{L}$ rat plasma in a $10 \mathrm{~mL}$ of polypropylene tube was mixed with $20 \mu \mathrm{L}$ hydrochloric acid (2 mol / $\mathrm{mL}$ ) and vortexed for $30 \mathrm{~s}$. Then the mixture was added into $100 \mu \mathrm{L}$ of IS solution $(0.986 \mathrm{mg} / \mathrm{mL}$ ) and vortexed for 60 s. After being placed in a water bath at $80^{\circ} \mathrm{C}$ for $30 \mathrm{~min}$ and the addition of ethyl acetate, the mixed solution was vortexed for 60 seconds and centrifuged for 10 minutes at $3000 \times \mathrm{g}$. The supernatants were transferred into other polypropylene tubes, and the residues were centrifuged at $3000 \times \mathrm{g}$ for $10 \mathrm{~min}$ after adding acetonitrile and vortexing for $60 \mathrm{~s}$. The two supernatants were merged firstly and then filtrated by microfiltration membrane, and finally dried under a nitrogen stream. Being dissolved in $500 \mu \mathrm{L}$ of methanol the residues were vortexed and $20 \mu \mathrm{L}$ solutions were analyzed in the UPLCESI-MS/MS system [15-17]. The samples were immediately centrifuged at $3000 \times \mathrm{g}$ for $10 \mathrm{~min}$ and stored at $-20^{\circ} \mathrm{C}$ until analysis.

\section{Method validation}

Based on the China Food and Drug Administration guidelines, the method was validated with respect to specificity, linearity and sensitivity, precision and accuracy, stability, and recovery.

\section{Specificity}

The specificity was performed by comparing the selected reaction monitoring (SRM) chromatograms of blank plasma and spiked plasma samples (including galangin, galangin-3methylether, kaempferide, kaempferol, quercetin and naringin (IS).

\section{Linearity and sensitivity}

Seven non-zero points of standard plasma samples were assessed in duplicate and analyzed in non - stop for 3 days for preparation of calibration curves. A weighted linear-squares regression model was used to establish the peak area ratio of the concentration of analytes versus standard plasma samples. The sensitivity was assessed by the lowest concentration on the calibration curve with a signal - to - noise ( $/ \mathrm{N}$ ) $\geq 10$ by analyzing six replicates. 


\section{Precision and accuracy}

Intra- and inter-day precision and accuracy of the analyzed samples were selected at three levels (high, medium, and low) in five replicates on 3 non - stop days. The precision and the accuracy were determined by the relative standard deviation (RSD) and the percent relative error (RE \%) respectively, and within $\pm 15 \%$ for the analyzed samples.

\section{Stability}

The stability of the five analytes in rat plasma was subjected to three different circumstances (storage for $12 \mathrm{~h}$ at ambient temperature, store at $-20{ }^{\circ} \mathrm{C}$ for three days, three cycles for freeze / thaw) at three different concentrations (high, medium, and low). All the samples were freshly prepared and the percentage deviation within \pm $15 \%$ were considered stable.

\section{Extraction recovery and matrix effects}

Matrix effects was assessed by comparing the peak areas of standard solutions spiked after extraction with those of the corresponding solution mixture (including galangin, galangin -3methylether, kaempferide, kaempferol, quercetin and IS) at three replicates concentrations (low, medium and high) in the same level. By comparing the peak areas of extracted samples (low, medium and high concentrations) with that of the standard solutions at the same concentrations with three replicates, the analytes' extraction recovery were assessed.

\section{Pharmacokinetic study}

The pharmacokinetic study of galangin, kaempferide, kaempferol, galangin-3-methylether and quercetin in rat plasma after intragastric administration of Shudage - 4 was successfully applied. Twelve wistar rats, six normal rats and six model rats, were fasted under normal conditions and given Shudage - $4(0.236 \mathrm{~g} / \mathrm{mL})$ by oral administration. $400 \mu \mathrm{L}$ of blood samples were obtained from the rat retro orbital plexus and injected into heparinized tubes at 10, 30, 60, $90,120,150,180,240,300,420$ and $480 \mathrm{~min}$.

\section{Statistical analysis}

DAS 2.1 software package was used to analyze the concentration-time data of the five analytes for the determination of the pharmacokinetic parameters. Differences in the parameters were evaluated by unpaired Student's $t$ - test with the aid of SPSS 20.0 software.

\section{RESULTS}

\section{Optimized LC-MS/MS for quantitative analysis}

The selected reaction monitoring (SRM) mode was selected for detection in the negative-ion mode. The optimized mass spectrometric parameters and mass spectra for all the analytes are shown in Figure 1, Figure 2 and Figure 3. The gradient elution system was used to chromatographic separation, which composed of $0.1 \%(\mathrm{v} / \mathrm{v})$ formic acid water solution (A) and methanol (B) containing $0.1 \%(v / v)$ formic acid at a flow rate of $1 \mathrm{~mL} / \mathrm{min}$. The gradient program follows: 0 - $3 \mathrm{~min}, 10 \% \mathrm{~B}-45 \% \mathrm{~B} ; 3$ - $6 \mathrm{~min}, 45$ $\%$ B - $65 \%$ B; 6 - 19 min, $65 \%$ B - $85 \%$ B; 19 $25 \min , 85 \% \mathrm{~B}-100 \% \mathrm{~B}$.
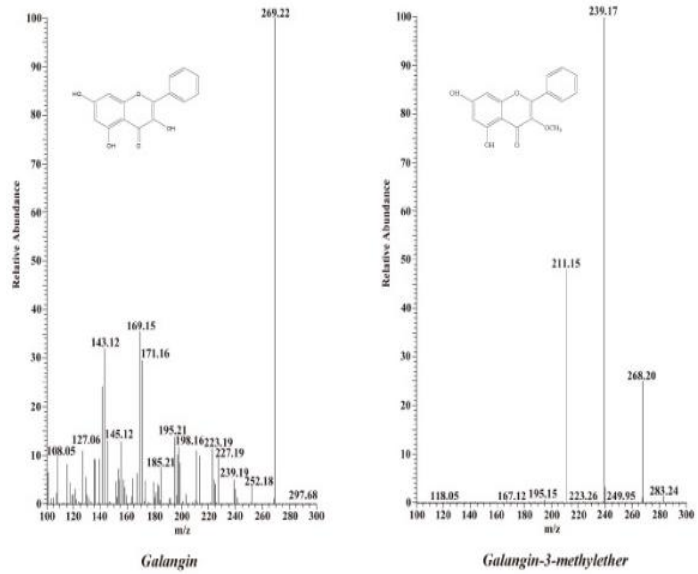

Figure 1: Structure and product ions scan spectra of galangin and galangin - 3-methylether
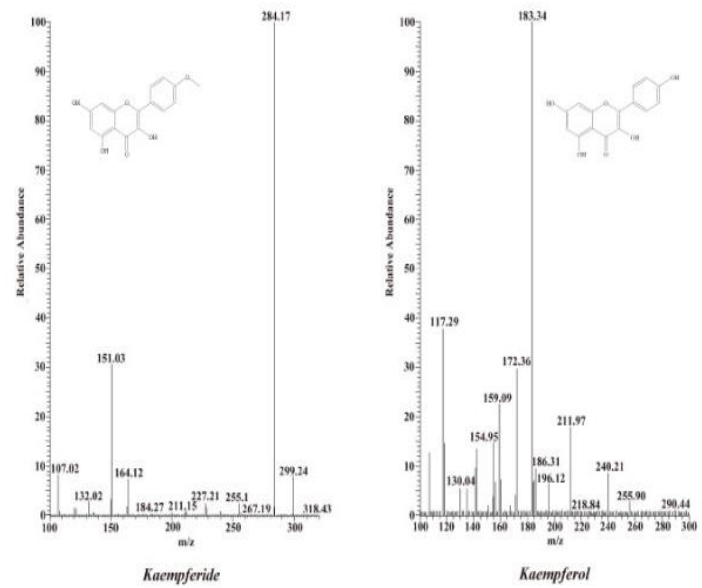

Figure 2: Structure and product ions scan spectra of kaempferide and kaempferol 

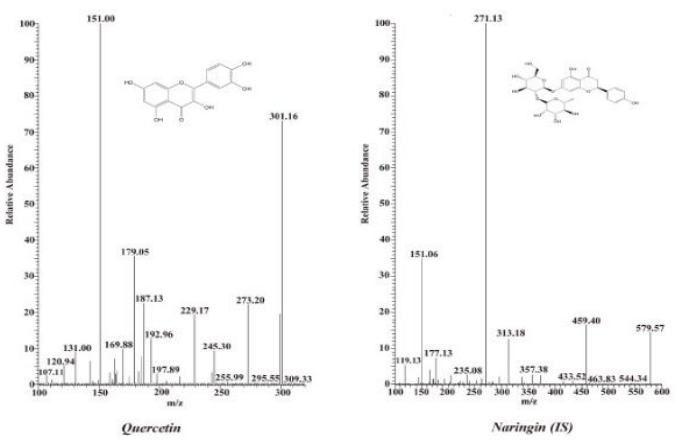

Figure 3: Structure and product ions scan spectra of quercetin and naringin (IS)

\section{Method validation results}

\section{Specificity}

As shown in Figure 4, Figure 5 and Figure 6, the specificity was assessed by comparing the chromatograms of blank plasma, spiked plasma samples and IS with good separation. The retention times were 14.46, 15.02, 14.14, 10.49 and $9.36 \mathrm{~min}$ respectively for the five analytes. IS was $7.38 \mathrm{~min}$. There was no interference between the five compounds and IS.

\section{Linearity and sensitivity}

The linear equations of galangin, galangin-3methylether, kaempferidel, kaempferol, quercetin and their low limits of quantification (LLOQs) were listed in Table 1. The correlation coefficients $\left(r^{2}\right)$ were all above 0.99 for the five compounds and represents good linearity for the five analytes.

\section{Precision and accuracy}

The intra and inter day precision of the five compounds were shown in Table 2, and RSD \% were all less than $15 \%$. For the simultaneous quantitative analysis of the five analytes in rat plasma, the present method was feasible.

\section{Stability}

The stability of the five compounds were assessed under different conditions, including storage for $12 \mathrm{~h}$ at ambient temperature, store at $-20{ }^{\circ} \mathrm{C}$ for 3 days, and three cycles for freeze/thaw. The UPLC - ESI - MS / MS method was satisfied in stability for the simultaneous determination for the five analytes in rat plasma.
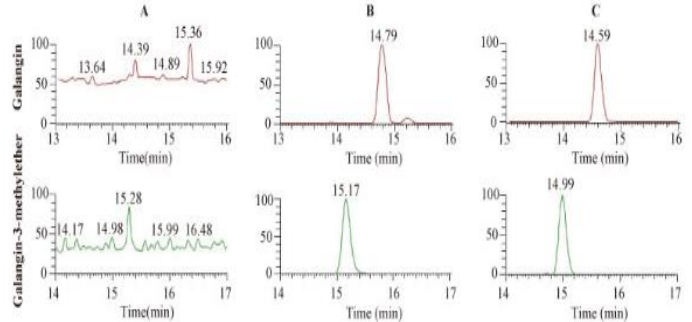

Figure 4: Typical chromatograms of galangin and galangin - 3 - methylether in rat plasma: $(A)$ blank plasma; (B) blank plasma mixed with galangin and galangin - 3 - methylether, (C) plasma samples collected from rats after $1.0 \mathrm{~h}$ after being given galangin and galangin - 3-methylether
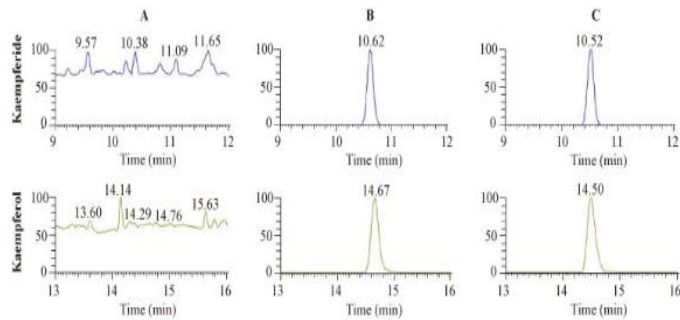

Figure 5: Typical chromatograms of kaempferide and kaempferol in rat plasma: (A) blank plasma; (B) blank plasma mixed with kaempferide and kaempferol; (C) plasma samples collected from rats after $1.0 \mathrm{~h}$ after being given kaempferide and kaempferol
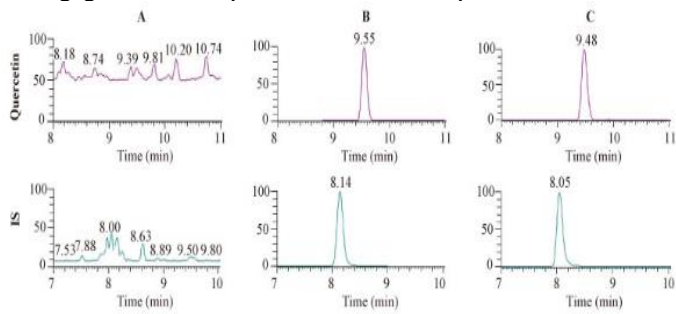

Figure 6: Typical chromatograms of quercetin and naringin (IS) in rat plasma: (A) blank plasma; (B) blank plasma mixed with quercetin and IS; (C) plasma samples collected from rats after $1.0 \mathrm{~h}$ after being given quercetin and IS

Table 1: The regression equations, linear range and LLOQs of the five analytes

\begin{tabular}{lllll}
\hline Compound & Regression equation & $\boldsymbol{r}^{\mathbf{2}}$ & Range $(\mathbf{n g} / \mathbf{m L})$ & LLOQ $(\mathbf{n g} / \mathbf{m L})$ \\
\hline Galangin & $\mathrm{y}=0.0045 x+0.003$ & 0.9990 & $229.8-22984.0$ & 229.8 \\
Galangin-3-methylether & $\mathrm{y}=0.1317 x+0.0017$ & 0.9996 & $32.0-3200.0$ & 32.0 \\
Kaempferide & $\mathrm{y}=0.1155 x-0.0138$ & 0.9992 & $78.8-7880.0$ & 78.8 \\
Kaempferol & $\mathrm{y}=0.0043 x-0.0007$ & 0.9996 & $123.7-12366.0$ & 123.7 \\
Quercetin & $\mathrm{y}=0.0083 x-0.0033$ & 0.9990 & $137.8-13780.0$ & 137.8 \\
\hline
\end{tabular}

$y=$ peak-area ratios of analytes to IS; $x=$ concentration of analytes in plasma (ng/mL), LLOQ = low limits of quantification 
Table 2: Intra and inter day precision and accuracy for the determination of the five analytes from the assay samples

\begin{tabular}{|c|c|c|c|c|c|c|c|}
\hline \multirow[b]{2}{*}{ Compound } & \multirow{2}{*}{$\begin{array}{l}\text { Spiked } \\
\text { conc.(ng/ } \\
\mathrm{mL})\end{array}$} & \multicolumn{3}{|c|}{ Intra-day $(n=3)$} & \multicolumn{3}{|c|}{ Inter-day $(n=5)$} \\
\hline & & $\begin{array}{l}\text { Mean conc. } \\
(\mathrm{ng} / \mathrm{mL})\end{array}$ & $\begin{array}{l}\text { Precision } \\
\text { (RSD, \%) }\end{array}$ & $\begin{array}{c}\text { Accuracy } \\
\text { (RE, \%) }\end{array}$ & $\begin{array}{l}\text { Mean conc. } \\
(\mathrm{ng} / \mathrm{mL})\end{array}$ & $\begin{array}{l}\text { Precision } \\
\text { (RSD, \%) }\end{array}$ & $\begin{array}{c}\text { Accuracy } \\
\text { (RE, \%) }\end{array}$ \\
\hline \multirow[t]{3}{*}{ Galangin } & 574.6 & 530.1 & 2.6 & -7.7 & 526.9 & 3.3 & -8.3 \\
\hline & 2298.4 & 2478.4 & 3.5 & 7.8 & 2521.0 & 1.2 & 9.7 \\
\hline & 22984.0 & 23159.9 & 1.6 & 0.8 & 22963.1 & 1.9 & -0.1 \\
\hline Galangin-3- & 80.0 & 86.4 & 7.4 & 8.0 & 85.8 & 6.1 & 7.3 \\
\hline \multirow[t]{2}{*}{ methylether } & 320.0 & 310.8 & 4.8 & -2.9 & 312.6 & 5.4 & -2.3 \\
\hline & 3200.0 & 3038.2 & 1.5 & -5.1 & 3052.4 & 3.7 & -4.6 \\
\hline \multirow[t]{3}{*}{ Kaempferide } & 197.0 & 186.3 & 5.5 & -5.4 & 189.5 & 3.0 & -3.8 \\
\hline & 788.0 & 797.6 & 4.6 & 1.2 & 796.5 & 2.0 & 1.1 \\
\hline & 7880.0 & 8020.4 & 1.6 & 1.8 & 8015.3 & 1.9 & 1.7 \\
\hline \multirow[t]{3}{*}{ Kaempferol } & 309.2 & 314.6 & 2.0 & 1.7 & 316.2 & 2.7 & 2.3 \\
\hline & 1236.6 & 1306.0 & 7.8 & 5.6 & 1310.4 & 4.8 & 6.0 \\
\hline & 12366.0 & 13453.0 & 6.8 & 8.8 & 13424.8 & 2.2 & 8.6 \\
\hline \multirow[t]{3}{*}{ Quercetin } & 344.5 & 322.5 & 4.8 & -6.4 & 326.3 & 6.2 & -5.3 \\
\hline & 1378.0 & 1296.8 & 2.0 & -5.9 & 1278.4 & 4.4 & -7.2 \\
\hline & 13780.0 & 12074.0 & 3.1 & -12.4 & 11986.3 & 1.9 & -13.0 \\
\hline
\end{tabular}

Note: conc. $=$ concentration

\section{Recovery}

As shown in Table 3, all the extraction recoveries were higher than $88.7 \%$ at three levels. No significant matrix effect was observed and the matrix ratios were in range of $72.9-98.8 \%$ for plasma samples.

\section{Pharmacokinetic comparison}

The pharmacokinetic process of galangin, galangin - 3 - methylether, kaempferide, kaempferol and quercetin in normal and gastric ulcer rats were shown in Figure 3 and Table 4. It was found that the metabolism and transport of the five analytes in gastric ulcer rats were faster than that in normal rats after intra gastric administration of Shudage - 4 extracts. For galangin, kaempferide and kaempferol, the pharmacokinetic characteristics of elimination rate constant $(\mathrm{K})$ in normal rats were $9.83 \pm 2.08$, $29.65 \pm 2.30$, and $95.87 \pm 17.38$ (1 / $\mathrm{min}$ ), whereas these values in gastric ulcer rats were $1.36 \pm 0.43,5.83 \pm 1.80$, and $40.01 \pm 10.52(1 /$ min), which were significantly lower $(P<0.01)$ than the normal group.

The AUC (0-t) values of galangin - 3 methylether, kaempferide, kaempferol, and Quercetin in gastric ulcer rats were significantly decline $(P<0.01)$ to $39.72 \pm 4.86,109.38 \pm 8.43$, $476.49 \pm 26.01,160.44 \pm 2.09(\mu \mathrm{g} / \mathrm{mL} \cdot \mathrm{min})$; The $\mathrm{C}$ max values of kaempferide, kaempferol and quercetin were decline to $0.70 \pm 0.08(P<0.05)$, $3.78 \pm 0.04(P<0.01), 0.88 \pm 0.20(P<0.01)(\mu \mathrm{g}$ $/ \mathrm{mL}$ ) respectively.

Table 3: Recovery and matrix effect of the five analytes and IS in rat plasma (mean $\pm S D, n=6$ )

\begin{tabular}{lccccc}
\hline Compound & $\begin{array}{c}\text { Spiked conc. } \\
(\mathbf{n g} / \mathbf{m L})\end{array}$ & Recovery (\%) & RSD (\%) & Matrix effect (\%) & RSD (\%) \\
\hline galangin & 574.6 & $88.7 \pm 3.9$ & 4.4 & $90.5 \pm 1.9$ & 2.1 \\
& 2298.4 & $102.3 \pm 4.1$ & 4.0 & $72.9 \pm 3.0$ & 4.2 \\
galangin-3- & 22984.0 & $99.9 \pm 2.7$ & 2.7 & $87.2 \pm 1.4$ & 1.6 \\
methylether & 80.0 & $117.3 \pm 1.4$ & 1.2 & $81.0 \pm 1.6$ & 2.0 \\
kaempferide & 320.0 & $110.1 \pm 5.0$ & 4.6 & $98.8 \pm 1.9$ & 2.0 \\
& 3200.0 & $106.5 \pm 2.7$ & 2.5 & $92.8 \pm 2.1$ & 2.3 \\
kaempferol & 197.0 & $106.1 \pm 2.7$ & 2.6 & $79.0 \pm 0.7$ & 0.9 \\
& 788.0 & $107.4 \pm 2.7$ & 2.6 & $99.7 \pm 0.6$ & 0.6 \\
Quercetin & 7880.0 & $96.9 \pm 0.5$ & 0.5 & $81.2 \pm 1.6$ & 2.5 \\
& 309.2 & $93.3 \pm 3.0$ & 3.2 & $74.9 \pm 1.1$ & 1.5 \\
& 1236.6 & $89.7 \pm 0.5$ & 0.7 & $74.8 \pm 3.3$ & 4.4 \\
\end{tabular}

conc. $=$ concentration 
Table 4: Pharmacokinetic parameters for the five analytes in normal and model rats after oral administration of Shudage - 4 extract (mean $\pm S D, n=6)$

\begin{tabular}{llccccc}
\hline Compound & Group & $\mathbf{C}_{\max }(\boldsymbol{\mu g} / \mathbf{m L})$ & $\begin{array}{c}\mathbf{t}_{1 / 2} \\
(\mathbf{m i n})\end{array}$ & $\begin{array}{c}\mathbf{K} \\
(\mathbf{1} / \mathbf{m i n})\end{array}$ & $\begin{array}{c}\mathbf{A U C}(\mathbf{0}- \\
\mathrm{t})(\boldsymbol{\mu g} / \mathbf{m L} \cdot \mathbf{m i n})\end{array}$ & $\begin{array}{c}\mathbf{A U C}_{(0-\infty)} \\
(\boldsymbol{\mu g} / \mathbf{m L} \cdot \mathbf{m i n})\end{array}$ \\
\hline galangin & Normal & $0.60 \pm 0.02$ & $28.29 \pm 2.03$ & $9.83 \pm 2.08$ & $73.06 \pm 5.85$ & $74.57 \pm 6.69$ \\
& Model & $0.59 \pm 0.02$ & $28.65 \pm 3.15$ & $1.36 \pm 0.43^{\# \#}$ & $72.23 \pm 5.28$ & $73.85 \pm 5.87$ \\
galangin- & Normal & $0.61 \pm 0.02$ & $30.56 \pm 1.51$ & $37.79 \pm 8.62$ & $63.10 \pm 2.40$ & $65.01 \pm 2.43$ \\
3-methylether & Model & $0.46 \pm 0.10$ & $36.96 \pm 3.25^{\#}$ & $12.62 \pm 9.14^{\#}$ & $39.72 \pm 4.86^{\# \#}$ & $41.51 \pm 5.45^{\# \#}$ \\
kaempferide & Normal & $0.86 \pm 0.03$ & $41.71 \pm 15.64$ & $29.65 \pm 2.30$ & $148.96 \pm 3.99$ & $190.63 \pm 5.76$ \\
& Model & $0.70 \pm 0.08^{\#}$ & $64.55 \pm 4.22$ & $5.83 \pm 1.80^{\# \#}$ & $109.38 \pm 8.43^{\# \#}$ & $168.86 \pm 5.61^{\# \#}$ \\
kaempferol & Normal & $4.29 \pm 0.07$ & $44.36 \pm 13.35$ & $95.87 \pm 17.38$ & $609.02 \pm 16.84$ & $637.59 \pm 28.83$ \\
& Model & $3.78 \pm 0.04^{\# \#}$ & $43.90 \pm 2.80$ & $40.01 \pm 10.52^{\# \#}$ & $476.49 \pm 26.01^{\# \#}$ & $494.51 \pm 24.81^{\# \#}$ \\
quercetin & Normal & $1.07 \pm 0.03$ & $41.95 \pm 16.08$ & $12.19 \pm 2.56$ & $208.23 \pm 8.78$ & $308.40 \pm 70.71$ \\
& Model & $0.88 \pm 0.20^{\# \#}$ & $55.806 \pm 3.394$ & $7.61 \pm 3.17$ & $160.44 \pm 2.09^{\# \#}$ & $282.47 \pm 62.00$ \\
\hline
\end{tabular}

${ }^{\#} p<0.05, \quad \# p<0.01$ (compared with normal group)
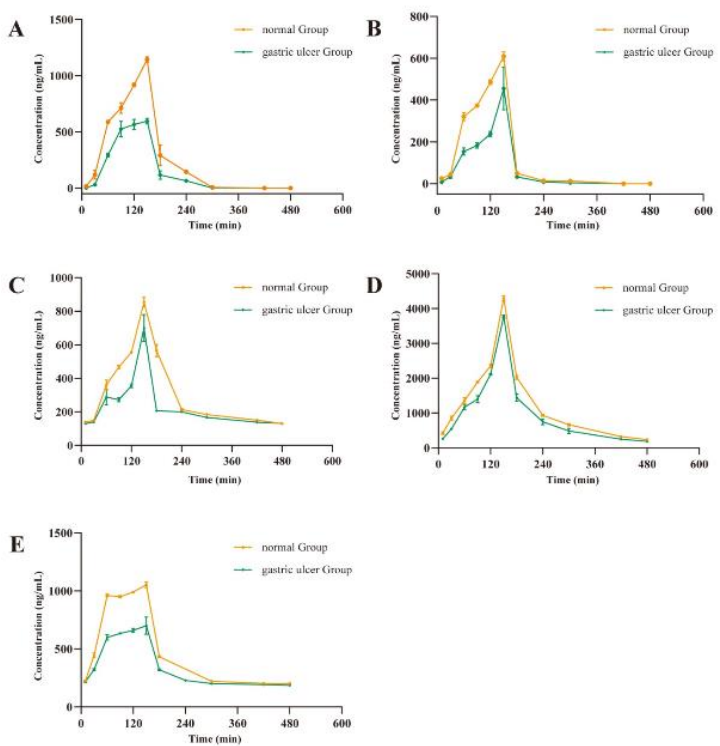

Figure 7: Mean plasma concentration - time curves of the five analytes in normal and gastric ulcer rats after oral administration of Shudage-4 extract. (A) galangin; (B) galangin-3-methylether; (C) kaempferide; (D) kaempferol; (E) quercetin

\section{DISCUSSION}

It has been used to treat stomach for thousands of years in Mongolia. A series of studies on the Mongolian medicine Shudage - 4 has been conducted in the early stage by our groups, and the results of pharmacological experiments show that Shudage - 4 has a good effect on gastritis and gastric ulcer [13-15]. Phytochemical studies have revealed flavonoids are one of the main ingredients in Shudage - 4 [6-8]. The total flavonoids extracts of Shudage - 4 was purify and enriched by $A B$ - 8 macroporous adsorptive resins in our research, and the content of total flavonoids were over $80 \%$ [6 - 8]. The contents of galangin, galangin-3-methylether, kaempferide, kaempferol and Quercetin were all high determined by using HPLC [6-8]. Meanwhile, the five flavonoids ingredients had good pharmacological activities, which could be used as the representative components of Shudage-4 in the treatment of gastric diseases [13-15].

The pharmacokinetic parameters, including $\mathrm{K}$ for galangin, $\mathrm{t}_{1 / 2}, \mathrm{~K}$ and $\mathrm{AUC}$ for galangin - 3 methylether, $\mathrm{C}$ max, $\mathrm{K}$ and $\mathrm{AUC}$ for kaempferide and kaempferol, $\mathrm{C}$ max and AUC (0-t) for quercetin showed significant difference $(P<0.05)$ in the normal and gastric ulcer rats. The metabolism and transport of the Mongolian Medicine Shudage - 4 in gastric ulcer rats were faster than that in normal rats and one possible reason for these differences may be flavonoids ingredients of Shudage - 4 concentrated and consumed in the lesion site faster than the normal group. Double peaks of galangin, galangin - 3 methylether, and quercetin are shown in Figure 7 $A, B$ and $E$, and the results might be due to enterohepatic circulation. Flavonoids enter the blood circulation, firstly, they are carried from the liver to the small intestine, which process needs to pass through the bile duct; then be absorbed into blood by the gastrointestinal system [18]. Double-peak phenomenon of quercetin is controversial. According to one study, no doublepeak on quercetin [19], which is inconsistent with our results. Analysis of the cause may be due to the drug interactions. Drug interactions may influence the absorption and elimination of flavonoids.

\section{CONCLUSION}

The UPLC-ESI-MS/MS-based assay for the determination of galangin, kaempferide, galangin - 3 - methylether, kaempferol and quercetin at the same time from effective fraction of the Mongolian Medicine Shudage-4 in plasma has been successfully developed. All results of the methodology met the criteria of the guidelines of Chinese Food and Drug Administration (CFDA). Thus, the method is specific, sensitive, precise 
and stable. It was applied to the pharmacokinetic studies of the five flavonoids successfully from effective fraction of Mongolian Medicine Shudage - 4 in rat plasma. The in vivo pharmacokinetic data obtained in rat plasma also suggest the developed method would be suitable for use in research and clinical conditions.

\section{DECLARATIONS}

\section{Acknowledgement}

This work was supported by the Natural Science Foundation of Inner Mongolia Autonomous Region (the project no. 2019ZD16).

\section{Conflict of interest}

No conflict of interest is associated with this study.

\section{Contribution of authors}

We declare that this work was undertaken by the authors named in this article, and all liabilities pertaining to claims relating to the content of this article will be borne by the authors. Yu Dong did the study design. Xin Jia and Yinfei Du processed the data and were responsible for data collection. Xin Jia and Jia Xu handled manuscript writing. Xin Jia and Yinfei Du contributed equally to this work and should be considered a co-first author.

\section{Open Access}

This is an Open Access article that uses a funding model which does not charge readers or their institutions for access and distributed under the terms of the Creative Commons Attribution License (http://creativecommons.org/licenses/by/ 4.0) and the Budapest Open Access Initiative (http://www.budapestopenaccessinitiative.org/rea d), which permit unrestricted use, distribution, and reproduction in any medium, provided the original work is properly credited.

\section{REFERENCES}

1. National Pharmacopoeia Commission. Drug Standards of the Ministry of Health of the People's Republic of China: Mongolian Drugs Subpart. Hohhot: Inner Mongolia Science and Technology Press; 2016; $p 158$.

2. Li HF, Li YH, Wang Y, Wei N, Tan YF, Zhang JQ. Study on chemical constituents and pharmacological activities of galangal. Chinese J Exp Tradit Med Formu2014; 20(7): 236-244.
3. Wang R, Fei HX, Li XM, Liu H, Niu YC, Liu XM, Huang $S M$. Research progress of chemical constituents and pharmacological effects of Shichangpu. Chinese Arch of Tradit Chinese Med 2013;(7): 1606-1610.

4. Murni NS, Qamar UA, Siti SMS, Alhassan MA, Suganya $M$, Vikneswri $P$, Sharifah NASM, Alfi $K$, Jalifah $L$. Antioxidant an antidiabetic effects of flavonoids: a structure-activity relationship-based study. BioMed Res Int 2017; 1-14.

5. Shashank K, Abhay KP. Chemistry and biological activities of flavonoids: an overview. Scientific World J 2013; 1-16.

6. Jia X, Dong Y, Wu N. Determination of total flavonoids in Mongolian Medicine Sudage-4 by UV-Vis spectrophotometry. J Inner Mongolia Med Coll 2010; 32(3): 303-305.

7. Yang $Y$, Jia $X$, Dongu, Ma Q. Study on chemical composition of Mongolian Medicine Shudag-4. J Inner Mongolia Uni (Natural Science) 2013; 44(4): 392-396.

8. Xin SS, Du YF, Jia X, Dong Y. Separation and structure identification of chemical constituents of Mongolian medicine compound Dag-4. J Beijing Uni of Tradit Chinese Med 2016; 39(10): 945-948.

9. Huang $\mathrm{HZ}$, Yang D. Research progress on chemical constituents and pharmacological activities of Galangal. Guangdong Chem Ind2009; 36(1): 77.

10. Min-Ji C, Eun-Jung L, Jin-Sun Park, Su-Nam K, Eun-Mi Park, Hee-Sun K. Anti-inflammatory mechanism of galangin in lipopolysaccharide-stimulated microglia: critical role of PPAR- $y$ signaling pathway. Biochem Pharmac 2017; 10(7): 148-152.

11. Wei $H$, Peng $Y, M a G X, X u L J$, Xiao PG. Research progress on active ingredients and pharmacological effects of E. odoratum. Chinese TraditHerb Drugs2012; 43(3): 613-620.

12. Xiao PG. New compilation of traditional Chinese medicine records. Beijing: Chemical Industry Press; 2006.

13. Jia X, Xin SS, Yang Y, Dong Y. Study on the effect of Mongolian medicine compound Dag-4 on experimental gastric ulcer. J Inner Mongolia Med Uni 2013; 35(5): 381-384.

14. Xin SS, Yang Y, Bai P, Dong Y. Study on the anti-rat gastric ulcer effect of Mongolian medicine Shudag-4. J Beijing Uni Tradit Chinese Med 2015; 38(8): 524-528.

15. Du YF, Zhou XF, Xin SS, Yang Y, Dong Y. Effects and mechanisms of Mongolian Chinese compound prescription Dag-4 active site on experimental gastric ulcer. J Beijing Uni Tradit Chinese Med 2016; 39(10): 839-841.

16. Stefan KGG, Ravinder JS. LC-MS/MS in the clinical laboratory-where to from hereclin. Biochem Rev 2011; 32: 5-31.

17. Rhishikesh T, Yashpal SC, Nagsen G, Amy N, Richard C, Gerard C, Mark TD, Barry M, Kendra KS, Stephen IR, et al. Simultaneous LC-MS/MS analysis of eicosanoids and related metabolites in human serum, sputum and BALF. Biomed Chromatogram 2018; 32(3).

Trop J Pharm Res, March 2020; 19(3): 658 
18. Guo DY, Dang JL, Yang H, Fan Y, Cheng JX, Shi YJ, Zhang XF, Zou JB. Simultaneous determination of four flavonoids in rat plasma after oral administration of Malus hupehensis (Pamp.) Rehd. extracts by UPLCMS/MS and its application to a pharmacokinetics study. J Pharmaceu and Biomed Anal 2019.

19. Wang T, Xiao J, Hou H, Li P, Yuan Z, Xu H, Liu R, Li Q, $\mathrm{Bi} K$. Development of an ultra-fast liquid chromatography-tandem mass spectrometry method for simultaneous determination of seven flavonoids in rat plasma: application to a comparative pharmacokinetic investigation of Ginkgo biloba extract and single pure ginkgo flavonoids after oral administration. $J$ Chromatogr B2017;2060. 